Check for updates

Cite this: RSC Adv., 2018, 8, 34202

\title{
Homoduplex to i-motif structural switch exhibited by a cytosine rich strand of the MYH7 heavy chain $\beta$ gene promoter at physiological $\mathrm{pH} \dagger$
}

\begin{abstract}
Anju Singh (iD) and Shrikant Kukreti (D) *
Genomic locations such as promoter, exon, intron, telomeric and non-telomeric regions are rich in GC-rich sequences with the potential to form G- and C-tetraplexes on both strands independently. Herein, we employed biophysical and biochemical methods to study a 34-mer C-rich DNA sequence of the myosin heavy chain $\beta$ gene (MYH7 $\beta$ ) promoter, namely HM34C for humans and the rabbit counterpart, RM34C, which differs from HM34C at three positions (three bases). Circular dichroism (CD), UV-thermal denaturation and native gel electrophoresis studies demonstrated that both the C-rich promoter segments form C-tetraplex (i-motif) structures. The CD studies revealed that HM34C forms the i-motif structure at acidic $\mathrm{pH}(5.2)$ in the presence of $0.1 \mathrm{M} \mathrm{NaCl}$ but remains unstructured at physiological $\mathrm{pH}$. Interestingly, RM34C can form the stable i-motif structure in acidic as well as physiological $\mathrm{pH}$. A shift in the positive peak from $280 \mathrm{~nm}$ to $275 \mathrm{~nm}$ with the increase in temperature from $4{ }^{\circ} \mathrm{C}$ to $30{ }^{\circ} \mathrm{C}$ was observed in temperature-dependent CD studies. UV-melting studies showed a biphasic transition for RM34C, indicating the existence of two structural species at neutral $\mathrm{pH}$. In view of these findings we suggest that at physiological $\mathrm{pH}$, the RM34C sequence exists in equilibrium between two structural motifs, i.e. the i-motif and homoduplex structure. This study may add to the understanding of the i-

motif/homoduplex in equilibrium in physiological environments.
\end{abstract}

Received 16th June 2018

Accepted 9th September 2018

DOI: $10.1039 / c 8 r a 05179 h$

rsc.li/rsc-advances

\section{Introduction}

Nucleic acids can adopt a variety of secondary structures depending on their sequence and their environment (solvent, ionic conditions, $\mathrm{pH}$ etc.). Apart from the twisted ladder-like double helical structure, DNA can adopt various non-B-DNA structures such as G-quadruplex, i-motif, H-DNA and cruciforms. Under physiological conditions, these non-B-DNA structures can prevail over DNA duplexes to regulate DNA processing or gene expression. ${ }^{1}$ It is well documented that consecutive runs of guanine, by virtue of self-association properties, have the tendency to fold into the G-quadruplex structure. With the formation of a G-quadruplex, the complementary C-rich strand becomes single-stranded, which should facilitate the folding into the i-motif form. For several G-rich sequences, including c-MYC, BCL-2, Rb, VEGF-A, RET, KRAS and c-Kit, the complementary cytosine-rich strand has been shown to form the i-motif structure. Initially, it was proposed that polycytidylic acid would form parallel duplexes at low $\mathrm{pH}^{2}$ The first detailed structure of the cytosine-rich sequence, $d($ TCCCCC), forming a tetrameric DNA structure with hemiprotonated $\mathrm{C}-\mathrm{C}^{+}$base

Nucleic Acids Research Lab, Department of Chemistry, University of Delhi, Delhi-110007, India.E-mail: skukreti@chemistry.du.ac.in

$\dagger$ Electronic supplementary information (ESI) available. See DOI: $10.1039 / \mathrm{c} 8 \mathrm{ra} 05179 \mathrm{~h}$ pairs, called the i-motif was reported in $1993^{3,4}$ The two parallel stranded $\mathrm{C} \cdot \mathrm{C}^{+}$(one cytosine must be hemiprotonated at the N3 position) base-paired duplexes intercalate into each other in an anti-parallel orientation. i-motif structures are the only known nucleic acid structures that involve base intercalation. It is interesting to note that $\mathrm{C}$-rich sequences with the potential to form i-motif structures are frequently found in eukaryotic genomes. ${ }^{5}$ The existence of the i-motif demonstrates most dramatically the wide range of structures that DNA can form. The three known topologies of i-motif structures are usually generated involving one, two or four strands. The most interesting differences are in the end effects observed in the loops of the folded structures and at the ends of the C-tetrameric structure. ${ }^{6}$

A short DNA oligomer d(TCC) having just two cytosines form the tetrameric i-motif. It is stabilized by a network of $\mathrm{C}-\mathrm{H} \cdots \mathrm{O}$ hydrogen bonding between neighboring deoxyriboses. Other stabilizing factors in i-motif that have been proposed in addition to hydrogen bonding between sugar residues are interactions between stacked $\mathrm{C}^{+} \cdot \mathrm{C}$ base pairs, stereoelectronic effects involving the sugar moiety, hydration, and hemiprotonated $\mathrm{C}^{+} \cdot \mathrm{C}$ pairs. However, very few reports are known about the formation of i-motif structures at neutral $\mathrm{pH} .{ }^{7-10}$ Mergny and coworkers have shown that a stretch of cytidines can form the imotif at slightly acidic or even neutral $\mathrm{pH} .^{7}$ It is reported that the DNA fragments of fragile $\mathrm{X}$ chromosomes can fold into i- 
motif structures at neutral $\mathrm{pH}^{8}{ }^{8}$ Interestingly, Waller et al. have reported a silver cation induced folding of a C-rich sequence into a stable i-motif structure. ${ }^{11}$ Zhou et al. have demonstrated that the i-motif structure can also be formed at neutral and slightly alkaline $\mathrm{pH}$ at $4{ }^{\circ} \mathrm{C}$, using $\mathrm{CD}$ (circular dichroism), UV absorption spectroscopy and PAGE (polyacrylamide gel electrophoresis). ${ }^{12}$

The present study is an attempt to see the possibility of the formation of i-motif structures by a genomic sequence at physiological $\mathrm{pH}$ and salt conditions. Here, we probed a C-rich sequence located in the promoter region of the Myosin Heavy Chain $\beta$ gene $(M Y H 7 \beta)$, for its i-motif-forming ability at neutral $\mathrm{pH}$. These sequences always co-exist with the G-rich counterpart in a gene. The biophysical studies were performed in varied solution conditions. Their structure, molecularity and stability were determined by non-denaturating gel electrophoresis (PAGE), UV-thermal denaturation and circular dichroism (CD) studies. This study may add to the understanding of the i-motif/ homoduplex in equilibrium under physiological solution environments.

\section{Materials and methods}

All the DNA sequences synthesized at $1 \mu \mathrm{M}$ scale were procured from Helix Biosciences (Delhi, India) in PAGE purified lyophilized form. Oligonucleotides were stored at $-20{ }^{\circ} \mathrm{C}$ and were used in the study without further purification. The concentrations of the DNA oligonucleotides were determined spectrophotometrically by using extinction coefficient $(\varepsilon)$ calculated by nearest neighbour approximation and measuring the absorbance at $260 \mathrm{~nm}$ at elevated temperature $\left(95^{\circ} \mathrm{C}\right)$, following the method described in literature. ${ }^{13-15}$ The stock solutions of all the DNA oligonucleotides including control size markers were prepared by directly dissolving the lyophilized powder in MilliQ water. All other fine chemicals were of analytical grade. The DNA sequences used in this study are summarized in Table 1.

\section{Non-denaturating gel electrophoresis}

The commercially procured oligonucleotides were subjected to denaturating gel electrophoresis to check the purity, by running them on $20 \%$ PAGE using $7 \mathrm{M}$ urea. After being assured about the purity, non-denaturating gel electrophoresis was carried out on $15 \%$ polyacrylamide gels (19:1 acrylamide/ bisacrylamide) to study their structural status. DNA samples of $15 \mu \mathrm{M}$ concentration were prepared in $20 \mathrm{mM}$ sodium cacodylate buffer (pH $5.7 \& 7.4$ ), $100 \mathrm{mM} \mathrm{NaCl}$ and $0.1 \mathrm{mM}$ EDTA. The final volumes of the samples in the buffer $(20 \mu \mathrm{L})$ were heat treated at $95{ }^{\circ} \mathrm{C}$ for $5 \mathrm{~min}$ and then slowly cooled to room temperature and were incubated overnight at $4{ }^{\circ} \mathrm{C}$. We used DNA oligonucleotides PAL12 (5'-CTTGAGCTCAAG- $\left.3^{\prime}\right)$, PAL24 ('5-CTTGAGCTTGAGCTCAAGCTCAAG-3'), M35 (5'-GACTGACTTAAGCGCATAGCTAGCTAGCTCGATAGCTGA-3 ${ }^{\prime}$ ) and M35C (5'-TCAGCTATCGAGCTAGCTAGCTATGCGCTTAAGTCAGTC-3') as control size markers. These deoxyoligonucleotides (control size markers) have frequently been used in the author's laboratory. ${ }^{16-19}$ PAL12 and PAL24 are palindromic DNA sequences that form 12-bp and 24-bp perfect duplexes in native conditions, whereas M35 and M35C are random markers complementary to each other. Samples were mixed with an aliquot of loading dye orange-G before loading on the gel. The gel was pre-equilibrated for one hour before loading the samples. After electrophoresis, the gel was stained with Stains-All solution and finally visualized under white light and images were taken by an Alphaimager ${ }^{\mathrm{TM}} 2200$ (Alpha Infotech Corp.).

\section{Circular dichroism spectroscopy}

The CD spectra of oligonucleotides were recorded on a CD spectropolarimeter, JASCO J-815, at room temperature $\left(24^{\circ} \mathrm{C}\right)$ using a quartz cuvette of $10 \mathrm{~mm}$ path length. Temperaturedependent CD experiments were performed at various temperatures. The cell holder was thermostated by a JASCO PTC-348 temperature controller and to avoid water condensation in the cuvette chamber, it was flushed with a constant purging of $\mathrm{N}_{2}$ gas. The CD spectra were collected from 330 to $200 \mathrm{~nm}$ at wavelength steps of $1 \mathrm{~nm}$, and the final reported spectra correspond to the average of three scans. The scans of buffer alone were subtracted from the average scans for each sample for baseline correction. Data were collected in units of millidegrees and were normalized to total DNA strand concentrations. Samples were prepared in $20 \mathrm{mM}$ sodium cacodylate buffer (pH 5.7 \& 7.4) containing $100 \mathrm{mM} \mathrm{NaCl}$ and $0.1 \mathrm{mM}$ EDTA. All samples used for CD were heat treated to $95{ }^{\circ} \mathrm{C}$ and slowly cooled at room temperature followed by overnight incubation at $4{ }^{\circ} \mathrm{C}$ to ensure that the $\mathrm{C}$-rich sequences folded to

Table 1 Oligonucleotide sequences used in the study

\begin{tabular}{|c|c|c|c|c|}
\hline S. no. & Name & Oligonucleotide sequences & Size & $\varepsilon\left(\mathrm{M}^{-1} \mathrm{~cm}^{-1}\right)$ \\
\hline 1 & HM34C & 5'-AGGGCACCCCCACCCCCAACGGCACCCAGTCCCT-3' & 34 & 302,100 \\
\hline 2 & RM34C & 5'-AGGGCGCCCCCACCCCCACCTGCACCCAGTCCCT-3' & 34 & 291,800 \\
\hline S. no. & Name & Control size marker & Size & $\varepsilon\left(\mathbf{M}^{-1} \mathrm{~cm}^{-1}\right)$ \\
\hline 1 & PAL12 & $5^{\prime}$-CTTGAGCTCAAG-3' & 12 & 113,700 \\
\hline 4 & M35C & 5'-TCAGCTATCGAGCTAGCTAGCTATGCGCTTAAGTCAGTC-3' & 35 & 333,100 \\
\hline
\end{tabular}


form i-motif structures or other stable higher secondary structures. It is a well-documented fact that G-quadruplex and Ctetraplex (i-motif) formation occur with a slow kinetics. We generally heat the samples up to $95{ }^{\circ} \mathrm{C}$ and then allow slow cooling at room temperature. As a result, all hydrogen bonds break during the nucleation process and then with slow cooling the proper renaturation/reannealing takes place, facilitating the formation of a thermodynamically stable conformation/ structure. This step is required specifically for $\mathrm{G} / \mathrm{C}$ rich oligos before every experiment (PAGE, $T_{\mathrm{m}}$, CD etc.) so that unwanted/ irregular secondary structure formation due to random hydrogen bonding can be avoided, along with facilitation of the formation of the stable secondary structure.

\section{UV thermal denaturation}

To elucidate the thermal stabilities of the secondary structures adopted by C-rich sequences (HM34C and RM34C), UV thermal melting was carried out in $20 \mathrm{mM}$ sodium cacodylate buffer $(\mathrm{pH}$ 5.7 \& 7.4) containing $100 \mathrm{mM} \mathrm{NaCl}$. Melting profiles were measured at 265 and $295 \mathrm{~nm}$ by using Shimadzu UV spectrophotometer 1800 equipped with a temperature controller. The stoppered quartz cuvette of $1 \mathrm{~cm}$ optical path length with $110 \mu \mathrm{L}$ was used for the melting experiments. The temperature was scanned at a heating rate of $0.5{ }^{\circ} \mathrm{C} \mathrm{min}^{-1}$. The analysis of the melting curves for the recorded melting profile was carried out using the first derivative.

\section{Results and discussion}

This study reports on the biophysical and biochemical investigations of C-rich DNA oligonucleotide sequences of promoter locations of the Myosin Heavy Chain $\beta$ gene ( $M Y H 7$ ) extracted from human (HM34C) and rabbit (RM34C) by using NCBI BLAST (https://blast.ncbi.nlm.nih.gov). The HM34C (AGGGCAC ${ }_{5} \mathrm{AC}_{5} \mathrm{AACGGCACCCAGTCCCT}$ ) sequence differs

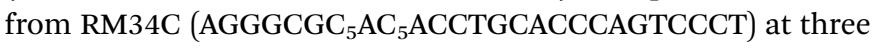
positions, viz. 6, 19, 21. These C-rich sequences were characterized under varied $\mathrm{pH}$ and temperature conditions, generating distinct sequence-dependent topologies including the $\mathrm{i}$ motif and homoduplex structure at neutral $\mathrm{pH}$ (7.4).

\section{Polyacrylamide gel electrophoresis (PAGE)}

Denaturating gel electrophoresis. To see if both $\mathrm{C}$ rich sequences remain unstructured/single-stranded under denaturating conditions urea-PAGE was performed. Fig. S1† depicts $20 \%$ denaturating gel electrophoresis containing $1 \times$ TBE and 100\% formamide for the sequences HM34C, and RM34C. M35 was used as the control size marker to check the mobility of bands in the gel. On comparing their mobility, it was found that all the sequences in (Fig. S1 $\dagger$ ) lanes 2-3 migrated according to their corresponding size. It was inferred that all the sequences used in this study exist as single strands under denaturating conditions.

\section{Non-denaturating gel electrophoresis}

Structural status of C-rich sequences at neutral $p H$ (7.4). Nondenaturating gel electrophoresis is a sensitive and informative
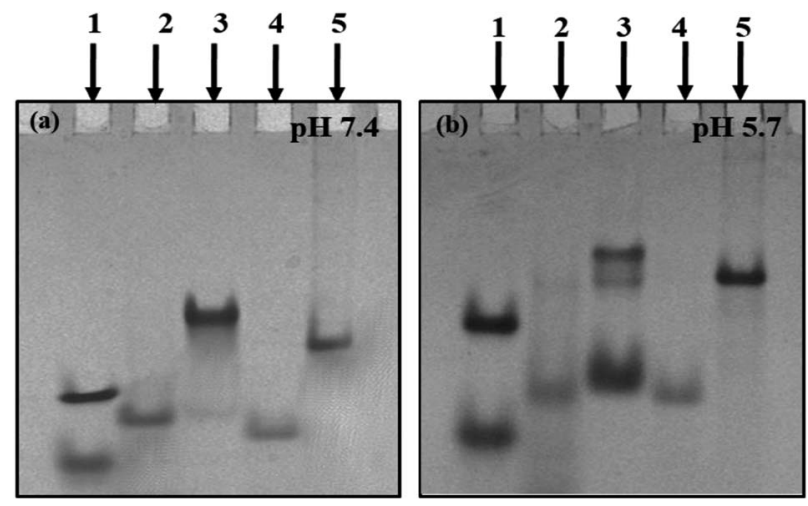

Fig. 1 15\% native PAGE mobility pattern of oligonucleotide sequences. Lane 1: PAL12 + PAL24, lane 2: HM34C, lane 3: RM34C, lane 4: M35, lane 5: M35 + M35C containing $0.1 \mathrm{M} \mathrm{NaCl}$ and $0.1 \mathrm{mM}$ EDTA in $20 \mathrm{mM}$ sodium cacodylate buffer at (a) $\mathrm{pH} 7.4$ and (b) $\mathrm{pH} 5.7$.

technique used to infer the molecularity/strandedness and folding status of oligonucleotides. This technique has been efficiently used to determine and differentiate various multistranded structures. After checking the purity of C-rich sequences, further native gel electrophoresis was performed to establish their structural status at varied solution conditions. Next, 15\% non-denaturating PAGE was carried out in $20 \mathrm{mM}$ sodium cacodylate buffer ( $\mathrm{pH} 7.4 \& 5.7$ ) containing $0.1 \mathrm{M} \mathrm{NaCl}$ and $0.1 \mathrm{mM}$ EDTA. Fig. 1(a) shows the electrophoretogram of HM34C and RM34C at neutral pH (7.4). PAL12 (12-mer duplexFig. 1(a)); lower band, lane (1), PAL24 (24-mer duplex-Fig. 1(a)); upper band, lane (1) are self-complementary palindromic duplexes, running as 24-base and 48-base oligomers in the native PAGE. Also, a random 35-mer single strand, size marker M35 (Fig. 1(a), lane (4) and a duplex of M35 + M35C (70 ntFig. 1(a)-lane (5)) were used as control oligomer marker. HM34C showed a single band (lane 2) migrating equivalent to M35, which indicates the unstructured status of C-rich strand. In contrast, RM34C (lane 3) exhibited two distinct bands, where the upper band was intense in comparison to the lower band. When compared to the gel markers, the mobility of the upper band of RM34C was found to be retarded in comparison to PAL24 (24-mer duplex) and the duplex of M35 + M35C (lane 5). Thus, the upper band of RM34C can be assigned to a bimolecular structure. The lower faint band migration corresponding to M35 can be assigned as unstructured RM34C. It is worth mentioning again here that RM34C and HM34C differ by three nucleotides. It was intriguing to observe that out of the two Crich sequences of identical length (34-mer), the RM34C sequence displayed retarded gel mobility at neutral $\mathrm{pH} 7.4$ (Fig. 1(a). This is only possible if the sequence experiences Cprotonation at $\mathrm{pH} 7.4$ and is involved in higher order structuration. We demonstrate here that RM34C adopts a bimolecular structure at neutral $\mathrm{pH}$.

Structural status of C-rich sequences at acidic $p H$ (5.7). As evident from the literature, cytosine protonation is a prerequisite for the formation of the i-motif, prone to form at low or acidic $\mathrm{pH}$. On the basis of the knowledge from the existing literature, gel studies were carried out at acidic pH 5.7 to 
facilitate cytosine protonation. Fig. 1(b) illustrates the mobility pattern of HM34C and RM34C in $20 \mathrm{mM}$ sodium cacodylate buffer (pH 5.7) containing $0.1 \mathrm{M} \mathrm{NaCl}$ and $0.1 \mathrm{mM}$ EDTA. Lanes 1, 4 and 5 were comprised of control size markers PAL12, PAL24 (lane 1), M35 (lane 4) and M35 + M35C (lane 5), respectively. Lane 3 showed two bands for $\mathrm{HM} 34 \mathrm{C}$, reflecting the presence of two structural species in solution. Based on their mobility pattern with respect to the size markers, the upper faint band (HM34C) migrates with the duplex of M35, indicating the bimolecular nature of HM34C. On considering the strand stoichiometry, it was thought to be the dimeric C-tetraplex (i-motif). The fast migrating band of HM34C can be of a folded unimolecular structure, as it was seen to migrate faster than M35. A lower intense band indicates a higher population of unimolecular species. In contrast, being of same length and sequence (except differing in three bases), RM34C (lane 3) exhibited three bands reflecting three distinct structural species in solution. The lower band (lane 3) migrated slower than M35 but faster than PAL24, and could be assigned to either unimolecular species or an unstructured single strand, while the middle band (lane 3) moved equivalent to the M35 + M35C duplex (lane 6) and could be the folded bimolecular structure involving two strands of RM34C, generating two interdigitated parallel duplexes (involving $\mathrm{C}: \mathrm{CH}^{+}$). The upper band, being intense, indicates that the bimolecular species is the dominant structure at low $\mathrm{pH}$. The uppermost band, when compared with the control size marker M35 + M35C, is shown to migrate slightly slower than the M35 duplex. Here, the possibility of formation of either the homoduplex or i-motif cannot be ruled out, as the same was found as the predominant species at physiological pH (Fig. 1(a), lane 3). It is, therefore, speculated that the uppermost intense band of bimolecular species (Fig. 1(b), lane 3), is structurally different from the middle band.

Further, to check the stability of the duplex and i-motif formed, the native gel was also run at $37{ }^{\circ} \mathrm{C}$ at varied $\mathrm{pH}(\mathrm{pH}$ 5.7 and 7.4) (Fig. S2(a \& b)†). The gel image showed the identical mobility pattern at $37^{\circ} \mathrm{C}$, as was obtained at $4{ }^{\circ} \mathrm{C}$ (Fig. 1(a and b)). The only difference observed was in the status of both the sequences (HM34C and RM34C) at pH 5.7. Here, at $37^{\circ} \mathrm{C}$, only a single intense band was observed, while the lower bands disappeared. However, HM34C (supplementary Fig. 2(a); lane 2) displayed a very intense band at $37^{\circ} \mathrm{C}$, indicating that only one structural species is stable at this temperature, in contrast to the $4{ }^{\circ} \mathrm{C}$ gel (Fig. 1(b); lane 2) where two bands were observed. The mobility patterns of HM34C and RM34C oligomers at physiological $\mathrm{pH}$ (7.4) were found to be almost similar at both the temperature values $\left(4^{\circ} \mathrm{C}\right.$ and $\left.37^{\circ} \mathrm{C}\right)$.

Structural status of RM34C in the presence of its G-counterpart $R M 34$ at neutral $p H$ (7.4). After examining the electrophoretic pattern of HM34C and RM34C at acidic as well as physiological $\mathrm{pH}$, to further establish the structural status of RM34C, we carried out a control gel experiment. To see whether RM34C exists as a self-associated structured species, which might further hinder its duplex forming ability with the complementary strand, it was titrated with increasing concentrations (50 picomoles to 250 picomoles) of G-rich RM34 $\left[5^{\prime}-\mathrm{TC}_{3} \mathrm{GCG}_{5} \mathrm{TG}_{5}{ }^{-}\right.$ TGGACGTGGGTCAG $\left.{ }_{3} \mathrm{~A}-3^{\prime}\right]$ in (Fig. 2).

Fig. 2 displays the gel image of RM34C alone and its mixture with G-rich RM34 at various ratios in $20 \mathrm{mM}$ sodium cacodylate buffer (pH 7.4), $0.1 \mathrm{M} \mathrm{Na}^{+}$and $0.1 \mathrm{mM}$ EDTA. On analysis, RM34C was found to exhibit its identical structural status as discussed earlier in gel, Fig. 1(a) (lane 3), where it migrated as a retarded band to the duplex (M35 + M35C size marker), clearly indicating self-structuration of RM34C at neutral pH. Lane $3 \rightarrow$ 5 displays two bands reflecting the presence of two structural species in solution. The lower band migration, equivalent to the M35 + M35C duplex, corresponds to the duplex species of RM34C + RM34, and the upper retarded band, migrating with the RM34C band, is interpreted as a bimolecular complex (Fig. 1(a)). It was observed that the intensity of the lower band increased, whereas the upper band disappeared with the addition of RM34 in increasing concentration. This clearly reflects

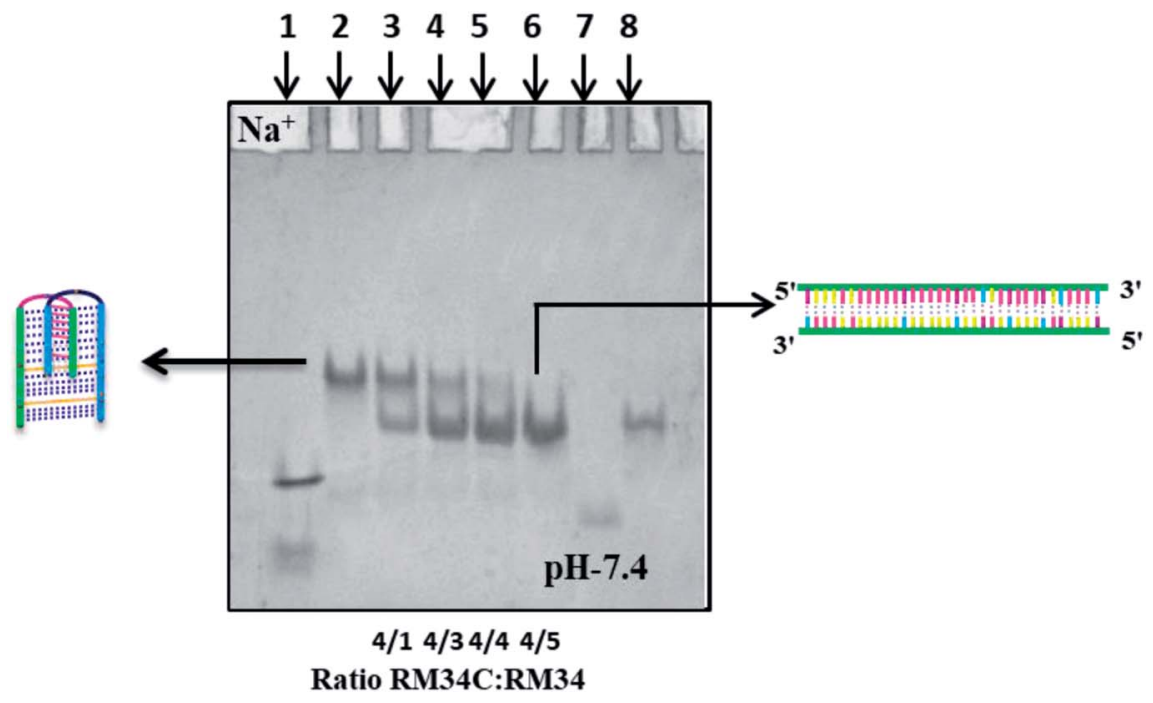

Fig. 2 The 15\% native PAGE mobility pattern of oligonucleotide sequences at pH 7.4. Lane 1: PAL12 + PAL24, lane 2: RM34C, lane $3 \rightarrow 6$ RM34C + RM34, lane 7: M35, lane 8: M35 + M35C containing $0.1 \mathrm{M} \mathrm{NaCl}$ and $0.1 \mathrm{mM}$ EDTA in $20 \mathrm{mM}$ sodium cacodylate buffer. 
the decrease in the population of self-associated bimolecular species of RM34C. Lane 6 showed a single intense band, migrating with the duplex of M35, consequently confirming the formation of a perfect Watson-Crick duplex between RM34C and RM34. The gel assay clearly demonstrates that due to the binding of the complementary RM34 to RM34C in varied ratios, the self-associated structure of RM34C is slowly destabilized resulting, in the formation of a perfect duplex with RM34. This control experiment further established the formation of a selfassociated complex by RM34C, which is most likely a bimolecular i-motif species, at neutral $\mathrm{pH}^{7}{ }^{7}$ It is important to mention here that although both the structures formed by RM34C (Fig. 2, lane-2) and the Watson-Crick duplex of RM34C + RM34 (Fig. 2, lane-6) are biomolecular (involving two strands), the difference in their gel mobility comes from the fact that while RM34C + RM34 is a compact Watson-Crick duplex, the self-associated biomolecular complex RM34C could be a partially folded interdigitated structure of two parallel duplexes involving $\mathrm{C} \cdot \mathrm{C}^{+}$ pairs. Such a self-associated structure, known as the i-motif, may have a retarded mobility compared to a compact duplex.

\section{Circular dichroism studies}

CD spectroscopy was carried out for secondary structure analysis and information on the conformational characteristics of the C-rich strands (HM34C and RM34C). The CD spectra of stacked $\mathrm{C} \cdot \mathrm{C}^{+}$base pairs in an i-motif are characterized by a positive band at $285-290 \mathrm{~nm}$ and a negative band centred at 260-268 nm..$^{\mathbf{2 0 2 1}}$ The CD spectra of HM34C and RM34C in $20 \mathrm{mM}$ sodium cacodylate $(\mathrm{pH} 7.4 \& 5.7)$ containing $0.1 \mathrm{M} \mathrm{NaCl}$ and $0.1 \mathrm{mM}$ EDTA are shown in Fig. 3(a and b). It is well documented that i-DNA is characterized by a typical positive CD signal at $286 \mathrm{~nm}$ followed by a negative peak at $265 \mathrm{~nm}$, whereas B-DNA-like structures exhibit a positive peak at $275 \mathrm{~nm}$ with a negative peak centred around $254 \mathrm{~nm} .^{22}$ The presence of a large positive peak at acidic $\mathrm{pH} 5.7$ towards longer wavelength near $286 \mathrm{~nm}$, followed by the appearance of a negative band around $\sim 260 \mathrm{~nm}$, is consistent with the well-documented features of stacked $\mathrm{C} \cdot \mathrm{C}^{+}$base pairs in an i-motif structure for all said oligonucleotides. i-Motif formation is sensitive to $\mathrm{pH}$ conditions and it is clearly shown in Fig. 3 depicting the CD status of all C-rich sequences at two different $\mathrm{pH}$ values 7.4 and 5.7. The amplitude of the positive band at $286 \mathrm{~nm}$ drastically increased when the $\mathrm{pH}$ of the sample solution was decreased from 7.4 to 5.7. The highest $\mathrm{CD}$ amplitude at $\mathrm{pH} 5.7$ corresponds to the formation of a maximum number of i-motif species (involving $\mathrm{C} \cdot \mathrm{C}^{+}$pairing) compared to their population at physiological $\mathrm{pH}$ (7.4). In the case of $\mathrm{HM} 34 \mathrm{C}$ at $\mathrm{pH} 7.4$, the positive maxima shifted towards $275 \mathrm{~nm}$ with a concomitant decrease in amplitude, indicating the lack of secondary structure, possibly due to deprotonation, resulting in unstructured C-rich single strands, whereas a sharp peak at $275 \mathrm{~nm}$ with significant amplitude was observed for RM34C (Fig. 3(b)), reflecting the presence of some self-associated structural species.

We presumed a fair possibility of parallel-stranded homoduplex formation here by $\mathrm{RM} 34 \mathrm{C}$ involving $\mathrm{C} \cdot \mathrm{C}^{+}$base pairing. This possibility was further investigated by temperature dependent CD measurements to clarify the structural status of RM34C.

Structural status of $\mathrm{RM} 34 \mathrm{C}$ at neutral $\mathrm{pH}$ by temperaturedependent CD. The formation of i-motif structures has been studied extensively in vitro, using various C-rich DNA sequences at acidic $\mathrm{pH}$. To date, there are very few studies reporting i-motif structure formation at neutral $\mathrm{pH}$. Mergny and coworkers have shown that a stretch of cytidines can form the i-motif at slightly acidic or even neutral $\mathrm{pH} .^{7}$ The DNA fragments of the fragile $\mathrm{X}$ chromosome can fold into the i-motif structure at neutral $\mathrm{pH}^{8}$ Zhou et al. also reported i-motif formation by $\left[\mathrm{C}_{3} \mathrm{TA}_{2}\right]_{3} \mathrm{C}_{3}(\mathrm{HT})$, $\left[\mathrm{C}_{4} \mathrm{G}\right]_{3} \mathrm{C}_{4} \mathrm{TA}$ (RET), $\mathrm{C}_{2} \mathrm{~T}_{3} \mathrm{C}_{2} \mathrm{~T}_{4} \mathrm{C}_{2} \mathrm{~T}_{3} \mathrm{C}_{2}$ (CTC) and $\mathrm{GC}_{2} \mathrm{GC}_{3} \mathrm{~A}_{4} \mathrm{C}_{6} \mathrm{G}$ $(\mathrm{Rb})$ at neutral and slightly alkaline $\mathrm{pH}$ at $4{ }^{\circ} \mathrm{C} .{ }^{12}$ It is now widely accepted that due to the deprotonation of cytosines at higher $\mathrm{pH}$ values $(\mathrm{pH}>7)$, the structure of the i-motif will convert into random coil conformation/unstructured single strands. However, under normal physiological cellular conditions, an intracellular $\mathrm{pH}$ was maintained in the range from 7.0 to 7.5. It is intriguing to investigate $\mathrm{i}$-motif formation at neutral $\mathrm{pH}$, to
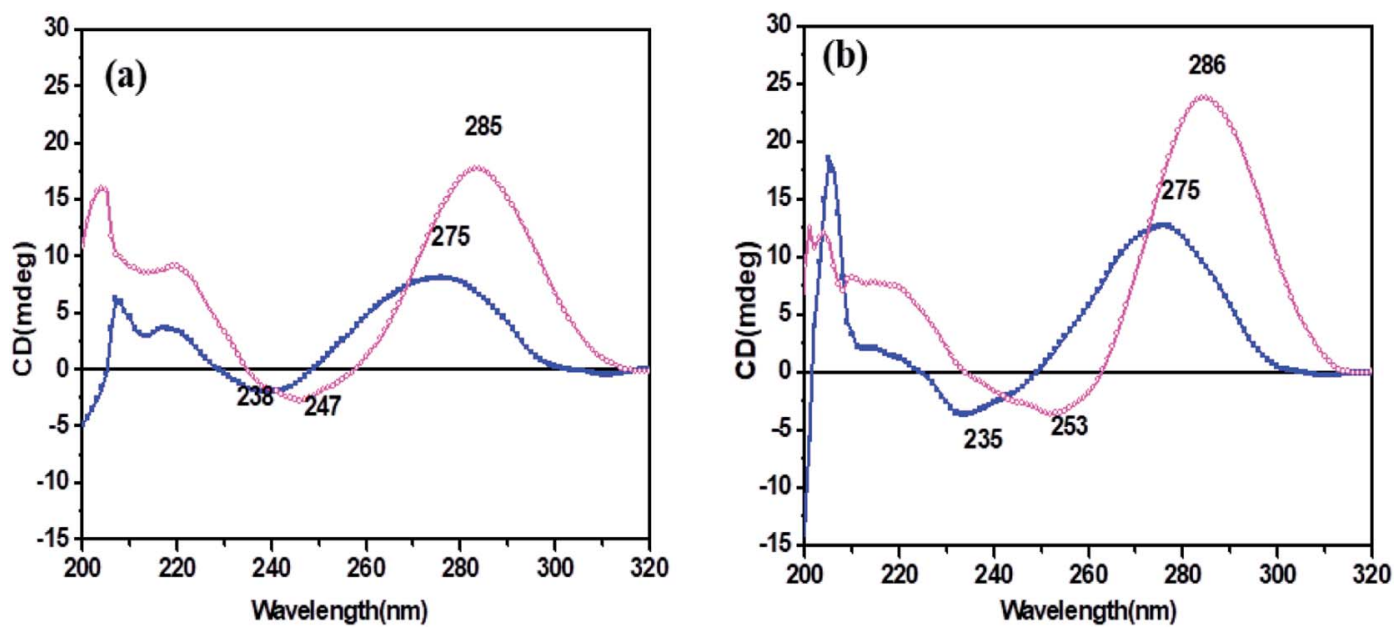

Fig. 3 CD spectra of (a) HM34C and (b) RM34C in 20 mM sodium cacodylate buffer, pH 7.4 (-a-) and pH 5.7 (-o-), containing $0.1 \mathrm{M} \mathrm{NaCl}$ and $0.1 \mathrm{mM}$ EDTA. 
speculate the biological role if any, under slightly alkaline conditions in vivo.

\section{Temperature-dependent CD studies}

Fig. 4 depicts the temperature-dependent CD spectra of RM34C at neutral $\mathrm{pH}$ of 7.4. A positive peak at $280 \mathrm{~nm}$ with a negative band centred at $244 \mathrm{~nm}$ at $4{ }^{\circ} \mathrm{C}$ indicate the cytosine-cytosine ${ }^{+}$ base pairing. Thus, the CD demonstrates that RM34C can form i-motif structures under neutral conditions at $4{ }^{\circ} \mathrm{C}$; however, the shift in the positive peak from $286 \mathrm{~nm}$ to $280 \mathrm{~nm}$ could be due to the decreased cytosine protonation at neutral $\mathrm{pH}$ in comparison to acidic $\mathrm{pH}$. With a gradual increase in temperature from $4{ }^{\circ} \mathrm{C}$ to $30{ }^{\circ} \mathrm{C}$, the $280 \mathrm{~nm}$ positive band is blue shifted to $275 \mathrm{~nm}$, following a decrease in the ellipticity.

At $30{ }^{\circ} \mathrm{C}$, the $\mathrm{CD}$ spectrum displayed positive and negative bands at $275 \mathrm{~nm}$ and $240 \mathrm{~nm}$, respectively. The amplitude of the CD spectrum does not fully correspond to any random coil/ unstructured species but indicates the possibility of formation of the homoduplex of RM34C. The size of this most probable homoduplex structure was established by native gel (Fig. 1(a), lane 3). Further, the occurrence of two isoelliptic points at $244 \mathrm{~nm}$ and $265 \mathrm{~nm}$ entail the transition between two discrete conformations (i-motif $\leftrightarrow$ homoduplex) and is a two-state process. Since we see a clear temperature dependence of CD signals, this undoubtedly reflects the transition of the i-motif to a homoduplex state at $30{ }^{\circ} \mathrm{C}$. The stabilities of these proposed structures adopted by $\mathrm{RM} 34 \mathrm{C}$ at neutral $\mathrm{pH}$ were further checked by thermal denaturation studies.

The structure of RM34C at physiological temperature, in the presence of its G-rich counterpart

CD titration studies were carried out to gain more insight into the structural switching shown by RM34C at physiological $\mathrm{pH}$, 7.4. Experimental solution conditions were kept similar to those used in the earlier section at $37{ }^{\circ} \mathrm{C}$. This study involved CD

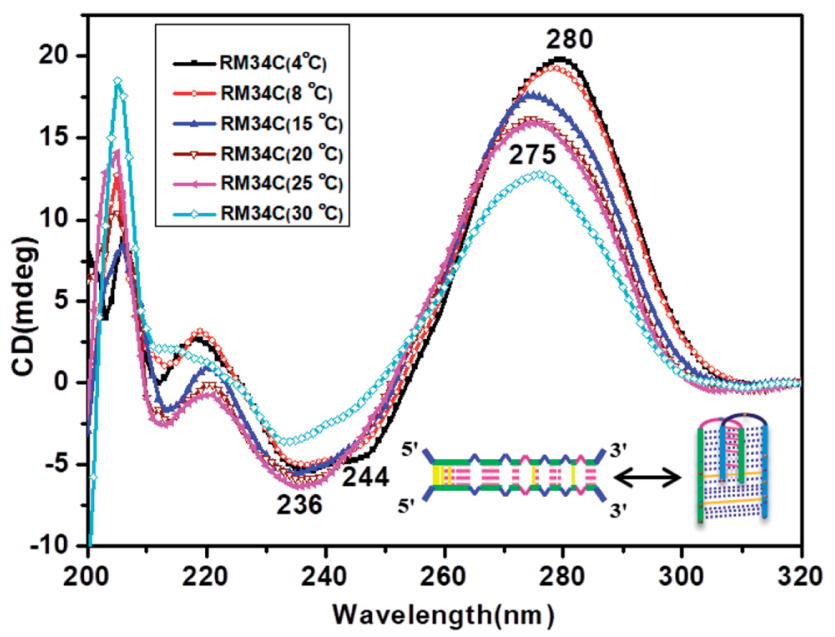

Fig. 4 Temperature-dependent CD spectra of RM34C in $20 \mathrm{mM}$ sodium cacodylate buffer $(\mathrm{pH} 7.4)$ and $0.1 \mathrm{mM}$ EDTA containing $0.1 \mathrm{M}$ $\mathrm{NaCl}$ at $4{ }^{\circ} \mathrm{C}(-\mathbf{-}-), 8{ }^{\circ} \mathrm{C}(-0-), 15^{\circ} \mathrm{C}(-\mathbf{\Delta}-), 20^{\circ} \mathrm{C}(-\nabla-), 25^{\circ} \mathrm{C}(-4-)$ and $30{ }^{\circ} \mathrm{C}(-\diamond-)$.

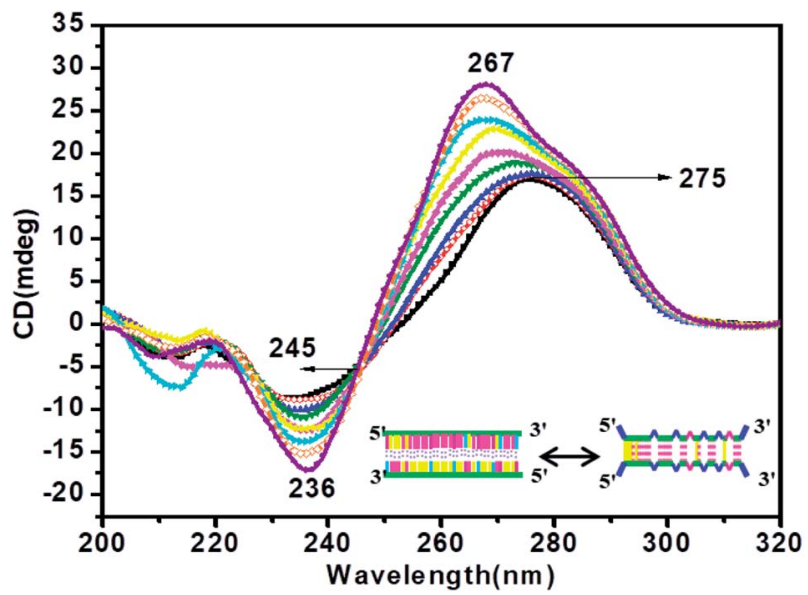

Fig. $5 \mathrm{CD}$ titration spectra of $\mathrm{RM} 34 \mathrm{C}$ at $37^{\circ} \mathrm{C}$ in $20 \mathrm{mM}$ sodium cacodylate buffer ( $\mathrm{pH} 7.4$ ) and $0.1 \mathrm{mM}$ EDTA containing $0.1 \mathrm{M} \mathrm{NaCl}$ at varied concentrations of RM34: $0.25 \mu \mathrm{M}(-0-), 0.50 \mu \mathrm{M}(-\mathbf{\Delta}-), 1 \mu \mathrm{M}$ $(-\mathbf{\nabla}-), 1.5 \mu \mathrm{M}(-\bullet-), 2 \mu \mathrm{M}(-4-), 2.5 \mu \mathrm{M}(-\bullet-), 3 \mu \mathrm{M}(-0-)$ and $3.5 \mu \mathrm{M}(-\bullet-)$.

measurements of gradual additions of G-rich RM34 to RM34C. The CD spectra manifested significant ellipticity, with a positive peak at $275 \mathrm{~nm}$ along with a negative peak centred at $236 \mathrm{~nm}$, indicating the formation of a structure adopted by RM34C at physiological $\mathrm{pH}$ and temperature (Fig. 5). CD spectra displayed in Fig. 5 , clearly show that on successive increments $(0.25 \mu \mathrm{M}$ to $3.5 \mu \mathrm{M}$ ) of RM34 to RM34C, positive CD peaks showed a further blue shift from $275 \mathrm{~nm}$ to $267 \mathrm{~nm}$. This transition is due to the formation of a new structural species, possibly a duplex formed between fully complementary sequences of RM34 and RM34C. The positive peak at $267 \mathrm{~nm}$ can be clearly assigned to the Watson-Crick duplex species of RM34C.

Interestingly, it is worth noting here that even when RM34 was added in excess to the RM34C, a minor population of structural species adopted by RM34C was also present $(\sim 275$ $\mathrm{nm})$, along with the perfect duplex of RM34 + RM34C $(\sim 267 \mathrm{~nm})$ (Fig. 5). The spectra depicted two positive peaks at $267 \mathrm{~nm}$ and $275 \mathrm{~nm}$ with an isodichroic point centred at $245 \mathrm{~nm}$. The isodichroic point indicates the existence of two structural species in equilibrium. The CD titration results are in good agreement with the gel results, where RM34C is demonstrated as a bimolecular structured species and migrates slower than the compact perfect duplex of M35 + M35C. On the basis of the CD titration results, we propose that RM34C exists as two structural species at physiological $\mathrm{pH}$ and temperature, i.e., a bimolecular species (with bulges), and as a perfect duplex in the presence of its G-counterpart.

\section{The structure of RM34C at $4{ }^{\circ} \mathrm{C}$ in the presence of its G-rich counterpart}

For information on the structure of RM34C at physiological pH ( $\mathrm{pH}$ 7.4), CD titration studies were also carried out at $4{ }^{\circ} \mathrm{C} . \mathrm{CD}$ spectra of RM34C in the presence of its G-rich counterpart RM34 are depicted in Fig. 6. CD spectra at $4{ }^{\circ} \mathrm{C}$ were apparent with a positive peak at $280 \mathrm{~nm}$ and a negative peak centred at $244 \mathrm{~nm}$; as suggested earlier, this can be assigned to i-motif 


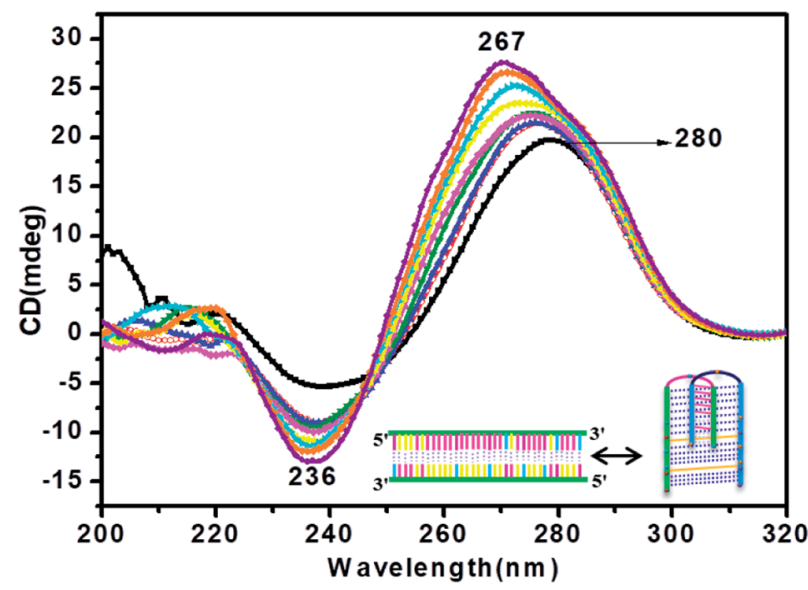

Fig. $6 \mathrm{CD}$ titration spectra of $\mathrm{RM} 34 \mathrm{C}$ at $4{ }^{\circ} \mathrm{C}$ in $20 \mathrm{mM}$ sodium cacodylate buffer ( $\mathrm{pH} 7.4$ ) and $0.1 \mathrm{mM}$ EDTA containing $0.1 \mathrm{M} \mathrm{NaCl}$ at varied concentrations of RM34: $0.25 \mu \mathrm{M}(-0-), 0.50 \mu \mathrm{M}(-\mathbf{\Delta}-), 1 \mu \mathrm{M}$ $(-\nabla-), 1.5 \mu \mathrm{M}(-\bullet-), 2 \mu \mathrm{M}(--)), 2.5 \mu \mathrm{M}(-\bullet-), 3 \mu \mathrm{M}(-\diamond-)$ and $3.5 \mu \mathrm{M}(-\bullet-)$

species. On the successive addition of complementary RM34 to RM34C, a prominent CD peak at $267 \mathrm{~nm}$ with increasing ellipticity and a blue shift was observed. There was also a minor positive peak at $280 \mathrm{~nm}$. The presence of the isodichroic point at $245 \mathrm{~nm}$ again reflects the existence of two structural species in equilibrium. Based on CD titration and gel studies at $4{ }^{\circ} \mathrm{C}$, it was established that RM34C might adopt the i-motif structure at low temperature, which turns into a duplex structure in the presence of its counterpart. This experiment confirms the structural transition of RM34C from i-motif to duplex species.

\section{UV-thermal denaturation studies}

Thermal stability in acidic pH. UV-thermal denaturation has been used to establish the formation of i-motif structures and their thermal stability. i-Motif formation is manifested with hyperchromism at $265 \mathrm{~nm},{ }^{23}$ whereas hypochromism at 295 $\mathrm{nm}^{7}$ is considered the signature of the presence of $\mathrm{C}-\mathrm{C}^{+}$base pairs. After examining the structural status by circular dichroism of the above mentioned DNA sequences, their thermal stability was investigated at acidic $\mathrm{pH}$ by thermal denaturation experiment in $20 \mathrm{mM}$ sodium cacodylate buffer (pH 5.7) containing $0.1 \mathrm{M} \mathrm{NaCl}$ and 0.1 mM EDTA. Fig. 7(a-d) display the melting profiles along with first derivative plots of HM34C and RM34C, respectively. All the monophasic sigmoidal melting transitions obtained were characterized by the sharp hyperchromic effect at $265 \mathrm{~nm}$ and by the sharp hypochromism (inverse sigmoidal) obtained at $295 \mathrm{~nm}$. An inverted melting profile at $295 \mathrm{~nm}$ represents a diagnostic feature for the i-motif structures. Such pH-dependent thermal profiles have been suggested previously for $\mathrm{C} \cdot \mathrm{C}^{+}$base pair stabilized i-motif structures. ${ }^{7,20}$

A nice cross-over was observed at 265 and $295 \mathrm{~nm}$ for all the $T_{\mathrm{m}}$ curves. Broad monophasic melting curves monitored at 265
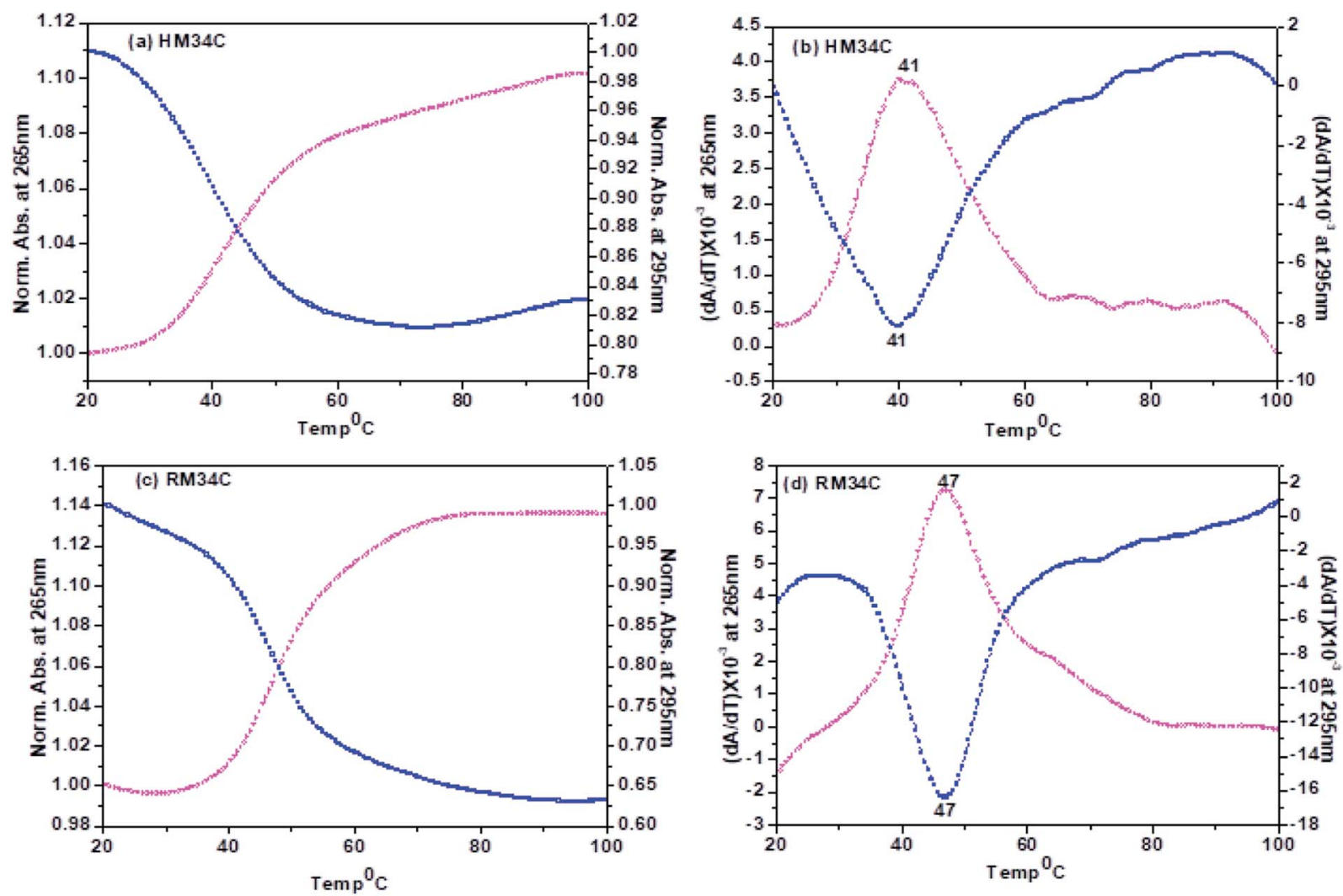

Fig. 7 Thermal denaturation profiles of (a) HM34C (normalized plot), (b) HM34C first derivative plot, (c) RM34C (normalized plot), (d) RM34C (first derivative plot) in $20 \mathrm{mM}$ sodium cacodylate buffer ( $\mathrm{pH}$ 5.7) containing $0.1 \mathrm{M} \mathrm{NaCl}$ and $0.1 \mathrm{mM}$ EDTA monitored at $265 \mathrm{~nm}$ and $295 \mathrm{~nm}$. 

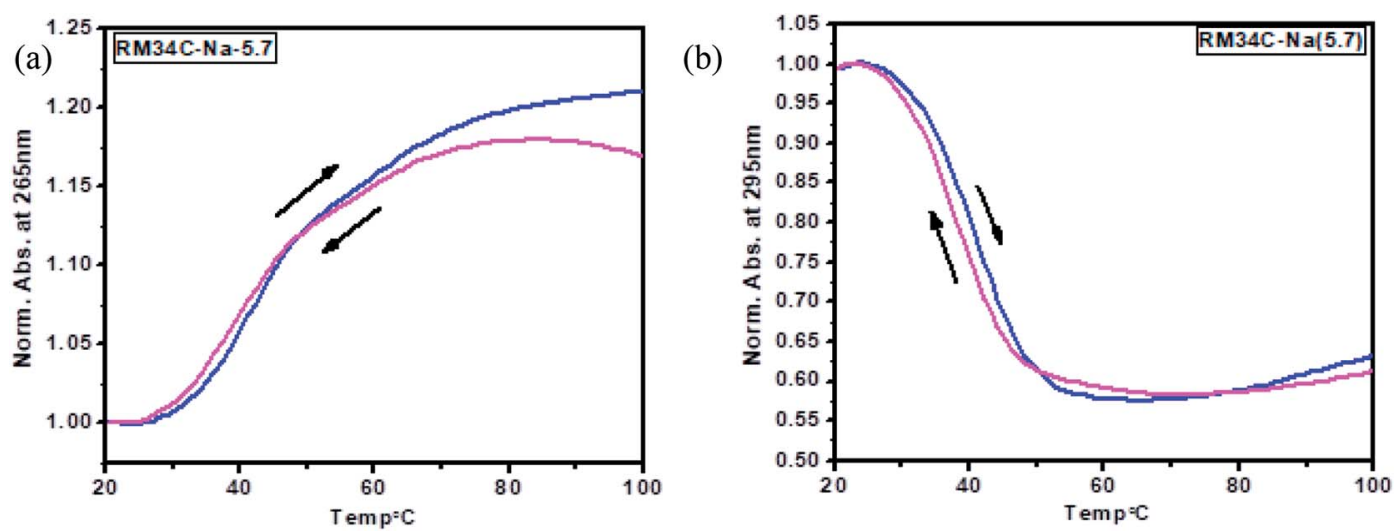

Fig. 8 Thermal denaturation and renaturation data for the $3 \mu M$ RM34C sequence at $265 \mathrm{~nm}$ (a) and at $295 \mathrm{~nm}$ (b), respectively. Samples were prepared in $20 \mathrm{mM}$ sodium cacodylate buffer at pH 5.7 containing $100 \mathrm{mM} \mathrm{NaCl}$ and $0.1 \mathrm{mM}$ EDTA, respectively.

and $295 \mathrm{~nm}$ were obtained for HM34C (Fig. 7(a)). The melting temperature calculated by the first derivative plot of both curves was found to be $41^{\circ} \mathrm{C}$ (Fig. 7(b)). Thus, it can be hypothesized that various structural species exist in solution conditions, which have approximately the same stability in solution and they unfold as a single transition in melting studies. The $T_{\mathrm{m}}$ profiles were also obtained for RM34C at acidic pH. Fig. 7(c) displays the biphasic transition at both wavelengths for RM34C. $T_{\mathrm{m}}$ calculated by the first derivative plot shows a prominent peak at $47{ }^{\circ} \mathrm{C}$ with a slight hump at $65{ }^{\circ} \mathrm{C}$ (Fig. 7 (d)). It is clear from the thermal melting studies that all the C-rich sequences used in the present study (HM34C and RM34C) had an inverted melting transition, indicating the unfolding of i-motif structures with a fair possibility of the co-existence of said structures having varied molecularity/strandedness. The data on the thermal denaturation and renaturation of RM34C was recorded at pH 5.7 at $265 \mathrm{~nm}$ as well as $295 \mathrm{~nm}$ and given in Fig. 8. Nearreversible superimposition of heating and cooling traces indicates that the transitions were kinetically reversible.

Thermal stability of RM34Cat neutral $\mathbf{p H}$. Thermal denaturation experiments were performed to investigate the stability of the structural status of $\mathrm{HM} 34 \mathrm{C}$ and $\mathrm{RM} 34 \mathrm{C}$ at neutral $\mathrm{pH}$ in $20 \mathrm{mM}$ sodium cacodylate ( $\mathrm{pH} 7.4$ ) containing $0.1 \mathrm{M} \mathrm{NaCl}$ and $0.1 \mathrm{mM}$ EDTA. At neutral $\mathrm{pH}, \mathrm{HM} 34 \mathrm{C}$ did not give any melting profile, thus remaining as an unstructured single strand (data not shown), whereas RM34C exhibited a well-defined biphasic melting profile as shown in Fig. 9.

$T_{\mathrm{m}}$ calculated for the melting profile of RM34C was found to be $61{ }^{\circ} \mathrm{C}$ for the higher temperature transition, and $47^{\circ} \mathrm{C}$ for the lower temperature transition (small hump on the curve). There is a fair possibility that uncoiling of the homoduplex species occurred at $61{ }^{\circ} \mathrm{C}$, whereas disordering of the i-motif structure occurred at $47^{\circ} \mathrm{C}$. The small hump observed on the melting curve $\left(T_{\mathrm{m}}=47^{\circ} \mathrm{C}\right)$ reflects the minor population of the i-motif in comparison to the homoduplex species. The results of thermal melting studies are in good agreement with temperature dependence CD studies. An overlay of the thermal melting profile of $\mathrm{RM} 34 \mathrm{C}$ at both $\mathrm{pH}$ values (5.7 and 7.4) is also provided in the ESI as Fig. S3.†

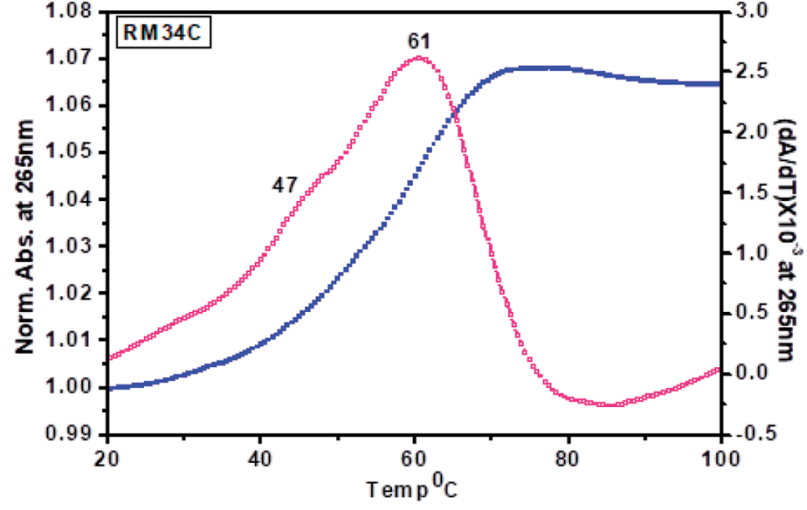

Fig. 9 Thermal denaturation profiles of RM34C in $20 \mathrm{mM}$ sodium cacodylate buffer ( $\mathrm{pH}$ 7.4) containing $0.1 \mathrm{M} \mathrm{NaCl}$ and $0.1 \mathrm{mM}$ EDTA, monitored at $265 \mathrm{~nm}$.

\section{Proposed models for the co-existence of the biomolecular homoduplex and i-motif structures}

Based on the experimental results of PAGE, $T_{\mathrm{m}}$ and CD studies, the most possible structural models for the studied C-rich sequences are proposed. The cartoons of the proposed structures formed by HM34C and RM34C at acidic, as well as neutral $\mathrm{pH}$ are presented in Fig. 11. Two gel bands obtained for HM34C migrated as bimolecular and unimolecular species. The possibility of non-Watson-Crick hydrogen bonding providing stability to proposed structures cannot be ruled out. It is a welldocumented fact that $G \cdot G$ mispairing contributes to greater thermal stability. ${ }^{24,25}$ The possible base pairing involved in imotif structures adopted by HM34C and RM34C are schematically presented in Fig. 10.

The formation of parallel bimolecular species (homoduplex) can be justified, as it can involve ten $\mathrm{C} \cdot \mathrm{C}^{+}$and two $\mathrm{G} \cdot \mathrm{G}$ hydrogen bonds, whereas the parallel dimeric i-motif may contain five $\mathrm{C} \cdot \mathrm{C}^{+}$pairs, which can further be stabilized by the possibility of the mismatch of two G.G, providing extra stability to the structure. It is important to remember that the CD spectra exhibited by C-rich sequences have also been observed by others 


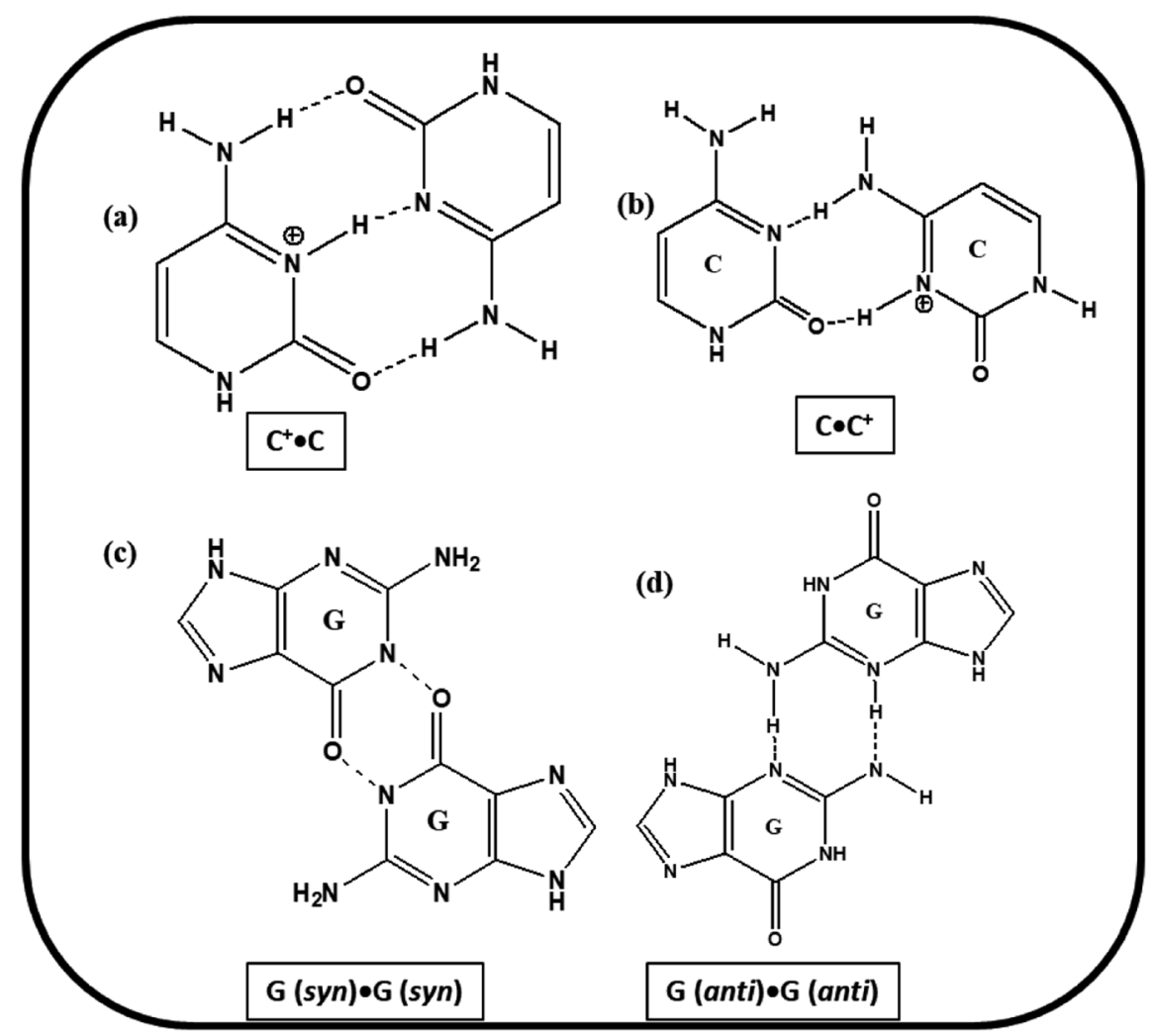

Fig. 10 Possible pairing scheme between the cytosine $\cdot$ cytosine $^{+}$(a) trans pair with hemiprotonated bases, (b) cis pair with one of the cytosines protonated. (c) Possible G(syn) $\cdot G($ syn) and (d) $G(a n t i) \cdot G(a n t i)$.

for a number of oligonucleotides containing varied numbers of cytosine residues. These reported structures, stabilised by $\mathrm{C} \cdot \mathrm{C}^{+}$ pairs, include parallel ${ }^{26,27}$ and antiparallel duplexes ${ }^{26}$ as well as parallel duplexes with looped out bases. ${ }^{28}$ Analogous models including hairpin structures have also been put forward based on experimental evidence. ${ }^{29}$ While the triple hydrogen-bonded $\mathrm{C} \cdot \mathrm{C}^{+}$trans pair, concomitant with anti $\mathrm{N}$-glycosidic conformations for all the cytosines, leads to the parallel alignment of the sugar-phosphate backbone chains, a different $\mathrm{C} \cdot \mathrm{C}^{+}$pair with only two hydrogen bonds (Fig. 10) could provide an antiparallel duplex ${ }^{26}$ as well as a hairpin structure. However, NMR studies on a number of cytosine-rich oligonucleotides, $\mathrm{d}\left(\mathrm{C}_{12}\right), \mathrm{d}\left(\mathrm{TC}_{3}\right)$, $\mathrm{d}\left(\mathrm{TC}_{3} \mathrm{~T}\right), \mathrm{d}\left(\mathrm{C}_{4} \mathrm{TC}_{4}\right), \mathrm{d}\left(\mathrm{T}_{2} \mathrm{C}_{8} \mathrm{~T}_{2}\right), \mathrm{d}\left(\mathrm{TC}_{4}\right), \mathrm{d}\left(\mathrm{TC}_{5}\right)$, and $\mathrm{d}\left(\mathrm{C}_{4}\right)$ have revealed a novel and unusual four-stranded structure arising from the antiparallel intercalation of two $\mathrm{C} \cdot \mathrm{C}^{+}$paired (triple hydrogen bond) parallel stranded duplexes, called i-DNA. ${ }^{3,30}$

Moreover, evidence has been provided that sequences containing four blocks of CCC of the human telomeric repeat adopt an intramolecular i-motif based structure. ${ }^{29,30} \mathrm{Here}$, the intramolecular i-motif is formed by $\mathrm{C}_{3}$ blocks of HM34C with two narrow loops harbouring CCA, AGT bases, and with a 9-baseswide loop CCAACGGCA (Fig. 11(a)). Interestingly, RM34C adopts the i-motif structure in acidic as well as neutral or physiological $\mathrm{pH}$ (7.4). On the basis of the molecularity/ strandedness of the structure through PAGE, the i-motif structure of RM34C was detected to be bimolecular. However, at neutral $\mathrm{pH}$, the possibility of homoduplex formation by two RM34C strands cannot be ruled out. Accordingly, the bimolecular parallel homoduplex proposed may contain four $\mathrm{G} \cdot \mathrm{G}$ hydrogen bonds at the $5^{\prime}$-end and two $\mathrm{G} \cdot \mathrm{G}$ mismatch at the $3^{\prime}$-side. These G.G mismatches could provide stability to these structures. The proposed model for RM34C at acidic $\mathrm{pH}$ and at neutral $\mathrm{pH}$ is represented in Fig. 11(b).

In theory, cytosine deprotonation should result in the instability of the i-motif, or even transition into a random coil at higher $\mathrm{pH}$ than 7 . However, previous reports have demonstrated that $\mathrm{C} \cdot \mathrm{C}^{+}$base pairs can be formed in hairpin and parallel duplexes at neutral and slightly alkaline $\mathrm{pH}^{31,32}$ Therefore, there is a fair possibility that $\mathrm{C} \cdot \mathrm{C}^{+}$base pairs are formed under normal physiological cellular conditions. Indeed, the stability of $\mathrm{C} \cdot \mathrm{C}^{+}$base pairs would be weak under such conditions. We observed the formation of the i-motif at low temperature in the case of $\mathrm{RM} 34 \mathrm{C}$, while at $37{ }^{\circ} \mathrm{C}$, the i-motif structures were converted to homoduplexes. Thus, besides the well-known effect of $\mathrm{pH}$, the temperature is also an important factor for the formation of i-motif structures.

\section{Biological relevance}

Non-canonical DNA topologies, such as DNA triplex, Gquadruplex, i-motifs, variants of unusual DNA structures, have attracted considerable attention from the scientific community for their potential role in gene regulation. The enrichment of guanine-rich sequences at promoters, telomeres, as well as various hot spot regions proved the substantial role of the Gquadruplex in the regulation of gene expression. ${ }^{33}$ 
(a)

HM34C 5'-AGGGCACCCCCACCCCCAACGGCACCCAGTCCCT-3'

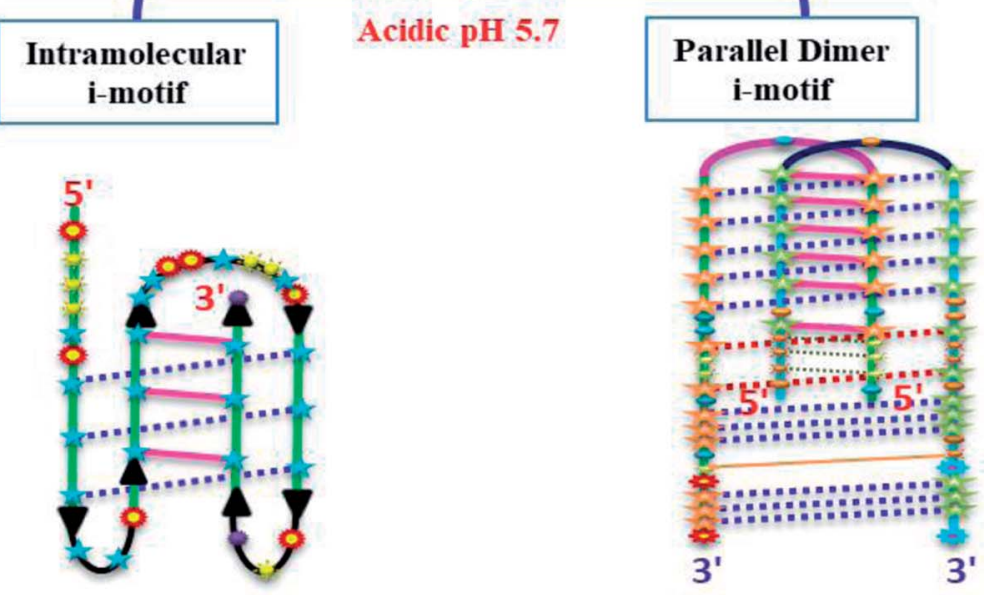

(b)

\section{RM34C 5' -AGGGCGCCCCCACCCCCACCTGCACCCAGTCCCT-3'}
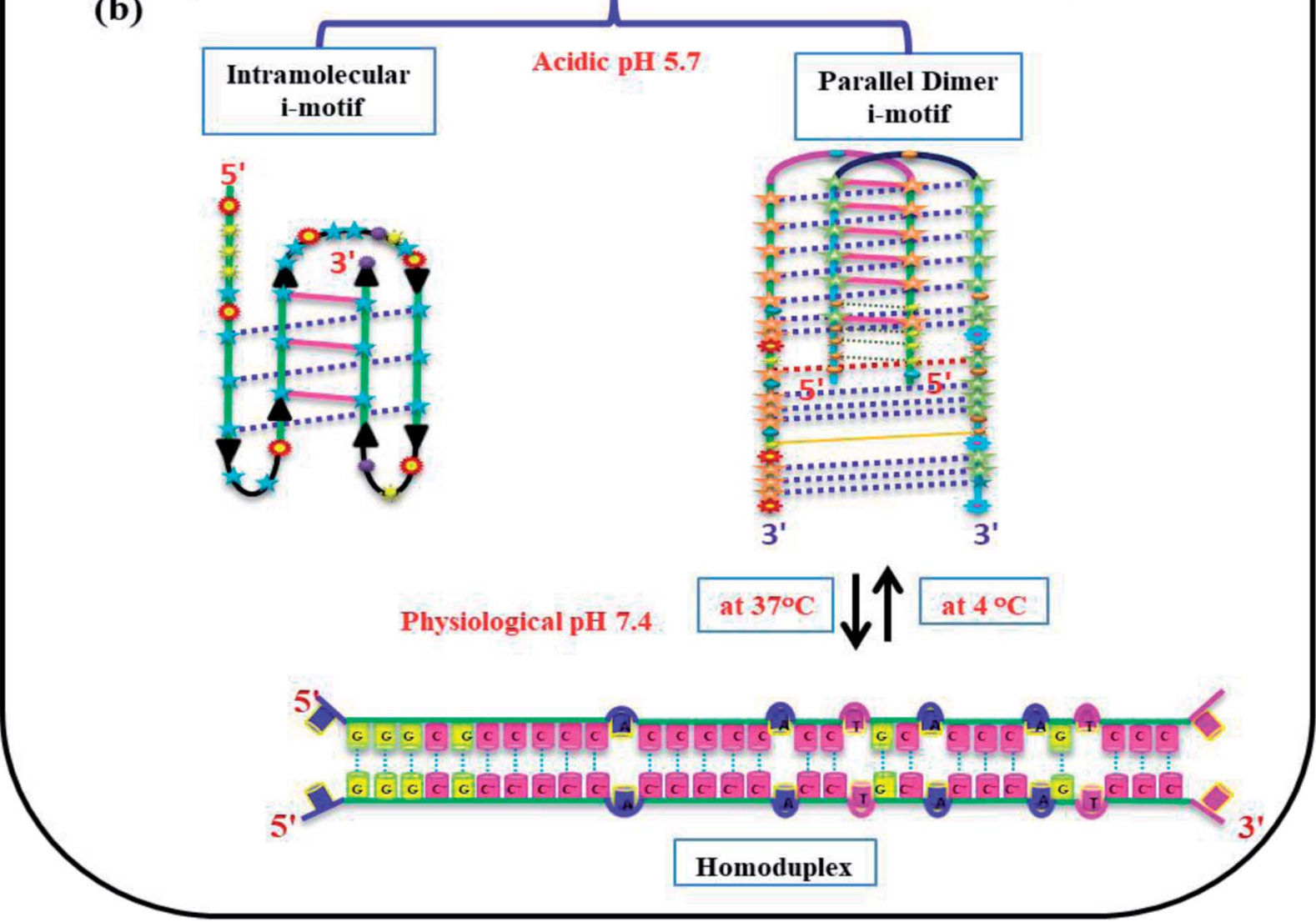

Fig. 11 Proposed model adopted by HM34C at acidic pH (5.7) (a) and RM34C at acidic pH (5.7) as well as physiological pH (7.4) (b).

Complementary counterparts of these G-rich sequences also tend to adopt C-tetraplex or i-motif structures, containing stacks of hemiprotonated $\mathrm{C}-\mathrm{C}^{+}$pairing. Under physiological conditions, $\mathrm{G}$ and $\mathrm{C}$ rich strands can adopt normal WatsonCrick duplex structures. Although both G and C-rich sequences experience the same cations and microenvironment, Gquadruplexes are unaffected by $\mathrm{pH}$, whereas cytosines get protonated at acidic $\mathrm{pH}$ and adopt intercalative DNA (i-motif) structures. It is well documented that while G-quadruplexes inhibit gene expression in some cases, i-motifs have the 
tendency to enhance transcriptional activity as well as their use as $\mathrm{pH}$-responsive switches in macromolecular assemblies. ${ }^{34-36} \mathrm{It}$ has been reported that in the influence of negative supercoiling, the i-motif formation takes place under physiological conditions. ${ }^{37}$ Moreover, since the i-motif has been shown to induce a pH-dependent conformational switch, these transient structures have potential applications in nanotechnology as nanomolecular devices. ${ }^{38-40}$ Recently, i-motif DNA nanomachines, functional between $\mathrm{pH} 5.5$ and 6.8, were constructed for application as $\mathrm{pH}$ sensors inside living cells. ${ }^{\mathbf{4 1}}$ The architecture of C-tetraplexes was found to be more complicated than Gtetraplexes due to the existence of C-rich sequences in imotifs, hairpin and homoduplex structures in equilibrium. ${ }^{35,36}$ Uribe et al. have reported that i-motif structures formed within the C-rich sequence of the HIF- $1 \alpha$ promoter can exist under physiological conditions and that hnRNP $\mathrm{K}$ can bind to this $\mathrm{C}$ rich sequence. ${ }^{42}$ Yunxi et al. have reported that small molecules like IMC-48, IMC-76 and hnRNP LL can interact with the i-motif and modulate the transcription of the BCL-2 gene. ${ }^{43}$

\section{Conclusion}

Based on the existing knowledge in literature, PAGE, circular dichroism (CD), and thermal denaturation profiles, it was concluded that all the C-rich sequences from the $M Y H 7$ gene promoter sequence studied here at acidic $\mathrm{pH}$ can adopt i-motif structures of varied molecularity/strandedness. The HM34C and $\mathrm{RM} 34 \mathrm{C}$ sequences depict the presence of two $\mathrm{C}_{5}$ and two $\mathrm{C}_{3}$ stretches separated by thymine $(\mathrm{T})$. It is evident here that RM34C forms the i-motif structure at acidic, as well as at neutral $\mathrm{pH}$. A very recent study by the Waller group demonstrated that $\mathrm{i}$ motif formation and its stability can be achieved without molecular crowding agents at physiological $\mathrm{pH}$, provided that there is a minimum tract length of $\mathrm{C}_{5}$. It is also established that more than half of the genomic oligonucleotides were shown to adopt the i-motif at neutral $\mathrm{pH}$. These C-rich sequences are not randomly distributed in the genome but they are predominantly found in gene promoters. ${ }^{44}$ This study strengthens our results that the $M Y H 7$ gene promoter sequence RM34C having $\mathrm{C}_{5}$ blocks can adopt the i-motif as well as homoduplex at physiological pH, whereas HM34C exists as an unstructured single strand at physiological $\mathrm{pH}$. These sequence motifs differ from each other by three bases. It is well documented that a single base difference in sequence is crucial for the regulation of its polymorphic nature and its pivotal role played in biological processes. ${ }^{45}$ The CD spectra cannot predict the molecularity/ strandedness of the i-motif topology (intramolecular, dimer or tetramer status), as all the three structures are formed by the interdigitation of two parallel duplexes involving $\mathrm{C} \cdot \mathrm{C}^{+}$pairs, which give identical CD bands irrespective of their molecular architecture. However, CD depicted all the signatures of the structures reported here, i.e., the i-motif, homoduplex and Watson-Crick duplex. Thus, it is clear from the temperature dependent CD studies that the structural status of the dimeric imotif changes at $37^{\circ} \mathrm{C}$. The $T_{\mathrm{m}}$ value of $61^{\circ} \mathrm{C}$ may be assigned to the structure that is stable at $37^{\circ} \mathrm{C}$ and is characterized by the
$+275 /-240 \mathrm{~nm}$ CD signal. Most probably, this could be a homoduplex structure stabilized by $\mathrm{G} \cdot \mathrm{G}$ and $\mathrm{C} \cdot \mathrm{C}^{+}$base pairs.

Although we are far from the clear picture of in vivo biological processes and with our studies we can only give an approximate idea about the structural polymorphism of said cytosine-rich sequences, we can still suggest that i-motifs can be formed not only under acidic conditions, but also at physiological pH and so may affect their possible biological roles. Nevertheless, more studies are required for the detailed description of i-motif formation and its topology in in vivo conditions for a better understanding of their recognition by proteins or any other important biological application.

\section{Conflicts of interest}

There are no conflicts to declare.

\section{Acknowledgements}

Authors would like to acknowledge University of Delhi for the research grant R\&D (RC/2015/9677-882) and DU-DST/PURSE Grant (CD/2015/1534).

\section{References}

1 C. Yunxi, K. D. Kong, G. Chiran, X. Cuixia and M. Hanbin, Mutually Exclusive Formation of G-Quadruplex and i-Motif is a General Phenomenon Governed by Steric Hindrance in Duplex DNA, Biochemistry, 2016, 55(15), 2291-2299.

2 R. Langridge and A. Rich, Molecular structure of helical polycytidylic acid, Nature, 1963, 198, 725-728.

3 K. Gehring, J. L. Leroy and M. A. Gueron, Tetrameric DNA structure with protonated cytosine-cytosine base pairs, Nature, 1993, 363, 561-565.

4 J. Fegion, A new DNA quadruplex, Curr. Biol., 1993, 3, 611613.

5 P. Catasti, X. Chen, S. V. Mariappan, E. M. Bradbury and G. Gupta, DNA repeats in the human genome, Genetica, 1999, 106, 15-36.

6 D. E. Gilbert and J. Fegion, Multistranded DNA structures, Curr. Opin. Struct. Biol., 1999, 9, 305-314.

7 J. L. Mergny, L. Lacroix, X. Han, J. L. Leroy and C. Helene, Intramolecular folding of pyrimidine oligodeoxynucleotides into anti-DNA motif, J. Am. Chem. Soc., 1995, 117, 8887-8898.

8 P. Fojtik and M. Vorlickova, The fragile X chromosome (GCC) repeat folds into a DNA tetraplex at neutral pH, Nucleic Acids Res., 2001, 29, 4684-4690.

9 X. Li, Y. Peng, J. Ren and X. Qu, Carboxyl-modified singlewalled carbon nanotubes selectively induce human telomeric i-motif formation, Proc. Natl. Acad. Sci. U.S.A., 2006, 103, 19658-19663.

10 C. Zhao, J. Ren and X. Qu, Single-walled carbon nanotubes binding to human telomeric i-motif DNA under molecularcrowding conditions: more water molecules released, Chem.-Eur. J., 2008, 14, 5435-5439.

11 H. A. Day, C. Huguin and Z. A. E. Waller, Silver cations fold imotif at neutral pH, Chem. Commun., 2013, 49, 7696-7698. 
12 J. Zhou, C. Wei, G. Jia, X. Wang, Z. Feng and C. Li, Formation of i-motif structure at neutral and slightly alkaline $\mathrm{pH}, \mathrm{Mol}$. BioSyst., 2010, 6, 580-586.

13 J. D. Puglisi and I. Tinoco Jr, Absorbance melting curves of RNA, Methods Enzymol., 1989, 180, 304-325.

14 N. Sugimoto, S. Nakano, S. Kotah, A. Matsumura, H. Nakamura, T. Ohmichi, M. Yoneyama and M. Sasaki, Thermodynamic parameters to predict stability of RNA/ DNA hybrid duplexes, Biochemistry, 1995, 34, 11211-11216.

15 S. Nakano, T. Kanzaki and N. Sugimoto, Influences of ribonucleotide on a duplex conformation and its thermal stability: study with the chimeric RNA-DNA strands, J. Am. Chem. Soc., 2004, 126, 1088.

$16 \mathrm{M}$. Kaushik and S. Kukreti, Structural polymorphism exhibited by a quasipalindrome present in the locus control region (LCR) of the human b-globin gene cluster, Nucleic Acids Res., 2006, 34(12), 3511-3522.

17 M. Kaushik, A. Bansal, S. Saxena and S. Kukreti, Possibility of an Antiparallel (Tetramer) Quadruplex Exhibited by the Double Repeat of the Human Telomere, Biochemistry, 2007, 46, 7119-7131.

18 M. Kaushik, M. Prasad, S. Kaushik, A. Singh and S. Kukreti, Structural transition from dimeric to tetrameric i-motif, caused by the presence of TAA at the $3^{\prime}$-end of human telomeric C-rich sequence, Biopolymers, 2010, 93(2), 150160.

19 S. Kaushik, M. Kaushik, F. Svinarchuk, C. Malvy, S. Fermandjian and S. Kukreti, Presence of divalent cation is not mandatory for the formation of intramolecular purine-motif triplex containing human c-junprotooncogene target, Biochemistry, 2011, 50(19), 4132-4142.

20 G. Manzini, N. Yathindra and L. E. Xodo, Evidence for intramolecularly folded i-DNA structures in biologically relevant CC-repeat sequences, Nucleic Acids Res., 1994, 22, 4634-4640.

21 H. Kanehara, M. Mizuguchi, K. Tajima, K. Kanaori and K. Makino, Spectroscopic evidence for the formation of four-stranded solution structure of oligodeoxycytidinephosphorothioate, Biochemistry, 1997, 36, 1790-1797.

22 J. Kypr, I. Kejnovská, D. Renčiuk and M. Vorlíčková, Circular dichroism and conformational polymorphism of DNA, Nucleic Acids Res., 2009, 37(6), 1713-1725.

23 J.-L. Leroy, J.-L. Mergny, M. Gueron and C. Helene, Intramolecular folding of a fragment of the cytosine-rich strand of telomeric DNA into an i-motif, Nucleic Acids Res., 1994, 22, 1600-1606.

24 S. H. Ke and R. M. Wartell, Influence of nearest neighbor sequence on the stability of base pair mismatches in long DNA: determination by temperature-gradient gel electrophoresis, Nucleic Acids Res., 1993, 21, 5137-5143.

25 E. M. Evertsz, K. Rippe and T. M. Jovin, Parallel-stranded duplex DNA containing blocks of trans purine-purine and purine-pyrimidine base pairs, Nucleic Acids Res., 1994, 22, 3293-3303.

26 D. M. Gray, T. Cui and R. L. Ratliff, Circular dichroism measurements show that C.C+ base pairs can coexist with
A.T base pairs between antiparallel strands of an oligodeoxynucleotide double-helix, Nucleic Acids Res., 1984, 12, 7565-7580.

27 E. L. Edwards, M. H. Patrick, R. L. Ratliff and D. M. Gray, A.T and C.C+ base pairs can form simultaneously in a novel multistranded DNA complex, Biochemistry, 1990, 29, 828836.

28 D. M. Gray and M. Vaughan, Circular dichroism spectra show that repeating dinucleotide DNAs may form helices in which every other base is looped out, Nucleic Acids Res., 1980, 8(16), 3695-3707.

29 S. Ahmed and E. Henderson, Formation of novel hairpin structures by telomeric C-strand oligonucleotides, Nucleic Acids Res., 1992, 20(3), 507-511.

30 J.-L. Leroy, K. Gehring, A. Kettani and M. Gueron, Acid multimers of oligodeoxycytidine strands: stoichiometry, base-pair characterization, and proton exchange properties, Biochemistry, 1993, 32, 6019-6031.

31 A. Yu, M. D. Barron, R. M. Romero, M. Christy, B. Gold, J. Dai, D. M. Gray, I. S. Haworth and M. Mitas, At physiological $\mathrm{pH}$, d(CCG)15 forms a hairpin containing protonated cytosines and a distorted helix, Biochemistry, 1997, 36, 3687-3699.

32 M. Vorlickova, I. Kejnovska, M. Tumova and J. Kypr, Conformational properties of DNA fragments containing GAC trinucleotide repeats associated with skeletal displasias, Eur. Biophys. J., 2001, 30, 179-185.

33 V. S. Chambers, G. Marsico, J. M. Boutell, M. D. Antonio, G. P. Smith and S. Balasubramanian, High-throughput sequencing of DNA G-quadruple structures in the human genome, Nat. Biotechnol., 2015, 33, 877-881.

34 S. Kendrick and L. H. Hurley, The role of G-quadruplex/imotif secondary structures as cis-acting regulatory elements, Pure Appl. Chem., 2010, 82, 1609-1621.

35 S. Kendrick, H.-J. Kang, M. P. Alam, M. M. Madathil, P. Agrawal, V. Gokhale, D. Yang, S. M. Hecht and L. H. Hurley, The Dynamic Character of the BCL2 Promoter i-Motif Provides a Mechanism for Modulation of Gene Expression by Compounds That Bind Selectively to the Alternative DNA Hairpin Structure, J. Am. Chem. Soc., 2014, 136, 4161-4171.

36 H.-J. Kang, S. Kendrick, S. M. Hecht and L. H. Hurley, The Transcriptional Complex between the BCL2 i-Motif and hnRNP LL Is a Molecular Switch to Control Gene Expression, J. Am. Chem. Soc., 2014, 136, 4172-4185.

37 D. Sun and L. H. Hurley, The importance of negative superhelicity in inducing the formation of G-quadruplex and i-motif structures in the c-Myc promoter: implications for drug targeting and control of gene expression, J. Med. Chem., 2009, 52, 2863-2874.

38 T. Liedl and F. C. Simmel, Switching the conformation of a DNA molecule with a chemical oscillator, Nano Lett., 2005, 5(10), 1894-1898.

39 E. Guittet, D. Renciuk and J.-L. Leroy, Junctions between imotif tetramers in supramolecular structures, Nucleic Acids Res., 2012, 40, 5162-5170. 
40 Y. C. Dong, Z. Q. Yang and D. S. Liu, DNA nanotechnology based on i-motif structures, Acc. Chem. Res., 2014, 47, 1853-1860.

41 S. Modi, M. G. Swetha, D. Goswami, G. D. Gupta, S. Mayor and Y. Krishnan, A DNA nanomachine that maps spatial and temporal $\mathrm{pH}$ changes inside living cells, Nat. Nanotechnol., 2009, 4, 325-330.

42 D. J. Uribe, Y.-J. Shin, E. Lau, S. W. Ebbinghaus and D. Sun, Heterogeneous Nuclear Ribonucleoprotein $\mathrm{K}$ Binds to the Cytosine-Rich Sequence of the Hypoxia Inducible Factor 1 Alpha Proximal Promoter that Forms a Stable i-motif at Neutral pH, J. Phys. Chem. Biophys., 2013, DOI: 10.4172/ 2161-0398.S5-001.
43 Y. Cui, D. Koirala, H. Kang, S. Dhakal, P. Yangyuoru, L. H. Hurley and H. Mao, Molecular population dynamics of DNA structures in a bcl-2 promoter sequence is regulated by small molecules and the transcription factor hnRNP LL, Nucleic Acids Res., 2014, 42, 5755-5764.

44 E. P. Wright, J. L. Huppert and Z. A. E. Waller, Identification of multiple genomic DNA sequences which form i-motif structures at neutral pH, Nucleic Acids Res., 2017, 45(6), 2951-2959.

45 D. Miyoshi, H. Karimata and N. Sugimoto, Drastic Effect of a Single Base Difference between Human and Tetrahymena Telomere Sequences on Their Structures under Molecular Crowding Conditions, Angew. Chem., Int. Ed., 2005, 44, 3740-3744. 